\title{
Association Between Components of Metabolic Syndrome and Cognitive Impairment among Middle-Aged and Elderly in Indonesia: A Nationwide Survey
}

\section{HUBUNGAN ANTARA KOMPONEN SINDROM METABOLIK DAN GANGGUAN KOGNITIF PADA USIA PARUH BAYA DAN LANSIA DI INDONESIA: SURVEI SECARA NASIONAL}

\author{
Sandy Ardiansyah ${ }^{*}$, Bayu Satria Wiratama², Shyh-Hsiang Lin ${ }^{3}$ \\ ${ }^{1}$ Department of Nutrition, Health Polytechnic of Ministry of Health, Bengkulu, Indonesia \\ 2 Department of Biostatistics, Epidemiology, and Population Health, Faculty of Medicine, Public Health, \\ and Nursing, Universitas Gadjah Mada, Yogyakarta, Indonesia \\ ${ }^{3}$ Master Program in Food Safety, Taipei Medical University, Taipei, Taiwan. \\ *Email corresponding author: sandy_ahligizi@ymail.com / ma07108020@tmu.edu.tw
}

\begin{abstract}
Cognitive impairment is common among population worldwide which become an increasingly important health issue related with aging. Indonesia is one of low-middle income countries with reach the era of aging, as the population aged 60 years and over is 10.0\% in 2020.The purpose of this study was to investigate associations between components of metabolic syndrome (MetS) and cognitive impairment among middle-aged and elderly Indonesians. Cognitively impaired was measured with the questionnaire derived from the instrument of telephone interview for cognitive status (TICS). Analysis of covariance was used to examine the differences and multivariate with logistic regression analysis of the odds of cognitive impairment. Setting on this study was using The Indonesia Family Life Survey (IFLS)-5 conducted in 2014-2015 with 1532 participants were placed into middle-aged and elderly. This study found that central obesity and dyslipidemia were less likely to have cognitive impairment among middle-aged and elderly. (OR adjusted for age and sex 0.67; 95\% CI $0.37 \sim 1.20 ; p=0.175)$. In conclucion, central obesity and dyslipidemia were less likely to have cognitive impairment among middle-aged and elderly in Indonesia. Our findings suggest that middle-aged people should manage their waist circumference in order to prevent cognitive impairment as they age.
\end{abstract}

Keywords: metabolic syndrome, obesity, cognitive impairment, Indonesia, IFLS-5

\section{INTRODUCTION}

Central obesity is one of components of metabolic syndrome (MetS) and a potential risk for cardiovascular diseases (CVDs). Over the past few decades, the prevalence of obesity has increased worldwide. Based on the National Health Survey of Indonesia (Riskesdas) data, obesity had reached $21.8 \%$ in that country (1). As one-third of adults are already overweight or obese, Indonesia is facing a healthcare challenge. The nutritional transformation theory suggests that economic growth, urbanization, and globalization contribute to increased intake of processed food and decreased physical activity, leading to higher prevalences of being overweight and suffering from noncommunicable diseases (2). 
Indonesia is the fourth most populous country in the world with around 267 million individuals, and has the largest developed economy in Southeast Asia (3). The processes of urbanization and industrialization are developing rapidly, and these have contributed to changes in the infrastructure in Indonesia. More than half of the population now lives in urban areas, and urbanization is increasing at a rate of $2.3 \%$ every year. Economic development and urbanization are related to lifestyles, diets, and physical activities (PAs) $(4,5)$. A previous study showed that the higher of prevalence obesity in Indonesia was due to increased consumption of meat and milk (6). Previous evidence from Indonesia and the Southeast Asian region showed that consumption of processed foods was significantly associated with consumption of meat, milk, and 'Western foods' among adults (7). Second, economic development and urbanization have also reduced PA levels and caused people to adopt more-sedentary lifestyles (8). Data on people with mild cognitive impairment (MCI) in Indonesia are still limited. In addition, no study has documented associations of central obesity with cognitive impairment in Indonesia.

Waist circumference (WC) is considered to be more precise than the body-mass index (BMI) and the most discriminating metabolic condition for the purpose of determining the likelihood of obesity-related comorbidities $(9,10)$. The population of the elderly in the world in 2015 had reached 900.9 million and is expected to increase by more than $60 \%$ by 2030 to 1402.4 million (11). An elderly person is someone who has reached the age of 60 years and over, based on Law Indonesia number 13 of 1998 that is concerned with elderly welfare. Indonesia is among five countries with the largest population of elderly people in the world. Based on statistics from the 2015 Inter-Census Population Survey (SUPAS), the number of elderly is 21.7 million or 8.5\%. Moreover, 11.6 million (52.8\%) were women and 10.2 million (47.2\%) were men (12). This indicates that Indonesia is one of the countries that will reach the era of ageing, when the population aged $\geq 60$ years exceeds $7.0 \%$. Changes in various systems in the body occur as a person gets older, and may include physical, psychological, and spiritual changes. One result of changes that occur in the elderly is cognitive impairment.

Based on the National Health Survey of Indonesia in 2018 (13), the most prevalent diseases in the elderly are degenerative diseases, including hypertension, diabetes mellitus, heart disease, stroke, and other infectious diseases such as upper respiratory tract infections, diarrhea, and pneumonia. There is an increasing trend of people living with dementia due to enhanced numbers of cases with non-communicable diseases. Therefore, the aim of this study was to investigate associations between components of MetS and cognitive impairment among middle-aged and elderly Indonesians using data from the Indonesia Family Life Survey (IFLS)-5.

\section{METHODS}

\subsection{Study Design and Study Population}

This cross-sectional study was conducted in 2014 and 2015 using data from the IFLS. In short, the IFLS was conducted by the RAND Corporation in collaboration with Lembaga Demografi, University of Indonesia (Jakarta, Indonesia), University of California, Los Angeles (UCLA; Los Angeles, CA, USA), and the Center for Population and Policy Studies, University of Gadjah Mada (Yogyakarta, Indonesia). The institutional review board (IRB) processed an adequate and precise review of using the IFLS data with registration number s0064-06-01- 
CR01, following IRB guidelines, and the study was approved by the RAND Corporation, the Indonesian Institute, and in particular, the Survey Meter Institute, which was given the task of working on the IFLS-5 study (14).

The total number of respondents in the IFLS dataset with cognitive data was 12,288 people aged from 0 to $>80$ years. Furthermore, complete data were collected relating to MetS components included anthropometric characteristics, and sociodemographic characteristics. Exclusion criteria were participants who had been diagnosed with cancer or a disability, or who were pregnant, to minimize the possibility of sampling bias. This study utilized a cohort of 1532 participants.

\subsection{Components of MetS}

This study used integrated IDF and AHA/NHLBI criteria to determine categories of MetS components (15), including (1) central obesity defined as a WC of $\geq 90 \mathrm{~cm}$ for men and $\geq 80 \mathrm{~cm}$ for women using Asian cutoff values; (2) hypertension as defined as systolic blood pressure (SBP) of $\geq 130 \mathrm{mmHg}$ or diastolic blood pressure (DBP) of $\geq 85 \mathrm{mmHg}$; (3) diabetes treatment used as a substitute for insulin resistance (IR) due to a lack of data on fasting plasma glucose levels; and (4) cholesterol treatment used as a substitute for low high-density lipoproteincholesterol (HDL-C).

\subsection{Cognitive Functioning}

The assessment of cognitive function was based on items derived from the instrument Telephone Interview for Cognitive Status (TICS). This instrument was administrated by face-to-face interviews with respondents $(14,16)$. Questions on the TICS include (1) the date, day, and year (9 points); (2) counting numbers (5 points); (3) recall of a 10 -word list (10 points); (4) recall of a 10-word list (10 points); (5) question block ( 3 points); (6) counting down backwards (1 point); (7) animals repeated (1 point); and (8) drawing two overlapping pentagons (1 point). The standard score ranged $0 \sim 40$ points categorized into no cognitive impairment (24 $\leq 40$ points); $\mathrm{MCI}(17 \sim 23$ points); and moderate cognitive impairment ( $\leq 17$ points) (17).

\subsection{Sociodemographics, BMI, PA, and Depression Status}

Sociodemographic data were collected using a questionnaire from the IFLS-5 related to gender, age, education, marital status, smoking habits, ethnicity, BMI, physical activity, and depression status. We calculated BMI in $\mathrm{kg} / \mathrm{m}^{2}$ and adopted WHO criteria of BMI with Indonesian cut-off points as those with a BMI of $<18.5$ $\mathrm{kg} / \mathrm{m}^{2}$ were categorized as being underweight, $18.5 \sim 25.0 \mathrm{~kg} / \mathrm{m}^{2}$ as having a normal weight, $25.1 \sim 27.0 \mathrm{~kg} / \mathrm{m}^{2}$ as being pre-obese, and $\geq 27.0 \mathrm{~kg} / \mathrm{m}^{2}$ as being obese (18). Smoking habits were summarized into never (never smoked), current smoker (currently smoked), and former smoker (previously smoked but had stopped). Educational levels were categorized into low ( $<12$ years of schooling) and high ( $\geq 12$ years of schooling).

The depression status was defined using 10 self-reported items derived from the Center for Epidemiological Studies-Depression (CES-D) questionnaire $(19,20)$. Answers to the 10 CES-D questions had four possible responses: "rarely or never" ( $\leq 1$ day), "some days" ( 1 or 2 days), "occasionally" ( 3 or 4 days), and "most of the 
time" (5 or 7 days). The score of each scale's answer was from zero ("rarely or never") to four ("most of the time"). We categorized having depressive symptoms as a score of $\geq 10$ from sum of the answers which ranged $0 \sim 30$ (20). Categories of physical activity were based on the International Physical Activity Questionnaire (IPAQ) Physical activity short version for the last 7 days (IPAQ-S7S) (21). The scoring protocol was categorized as low, moderate, and high. Two self-reported questions assessed the PA volume as units of the metabolic equivalent of one task-hour per week (MET-h/wk) (22).

\subsection{Statistical Analysis}

IBM SPSS Statistics version 21 (IBM, SPPS, Chicago, IL, USA) was used for all data analyses. Participants were separated into two groups of normal or no cognitive impairment and mild or severe cognitive impairment, categorized as having cognitive impairment. Analysis of differences in categorical variables used a Chisquared test. Furthermore, a multivariate analysis to measure individual components of MetS by risk factors for cognitive impairment after controlling for covariates used a Binary logistic regression.

\section{RESULTS}

\subsection{Characteristics of Respondents}

In total, 1532 participants with complete data about their cognitive status and MetS were enrolled in the study. As to age categories included this study, 53.8\% of participants were middle-aged and $46.2 \%$ were elderly. Table 1 shows the characteristics of respondents stratified into two age groups and cognitive impairment. There were significant differences in the proportions of middle-aged and elderly participants in terms of educational level and BMI with cognitive impairment $(p<0.005$ by a Chi-squared test).

\subsection{Associations between Components of MetS and Cognitive Impairment among}

\section{Middle-aged and Elderly Indonesians}

Table 2 shows associations between components of MetS among middle-aged and elderly Indonesians stratified by cognitive impairment. Results show that the prevalence of central obesity was higher in middle-aged than elderly participants. Furthermore, more subjects in the middle-aged group were undergoing cholesterol treatment than in the elderly group. There were significant differences in central obesity, dyslipidemia (cholesterol treatment), and cognitive impairment among middle-aged and elderly Indonesians $(p=0.05$ by a Chi-squared test).

\subsection{MetS, Five MetS Components, and Odds of Cognitive Impairment}

Participants with central obesity in model 1 and model 2 were associated with cognitive impairment (both $p<0.05$; Table 4). Dyslipidemia was significantly associated with cognitive impairment in our analyses (odds ratio (OR) $0.47,95 \%$ confidence interval (CI) 0.24-0.92, $p=0.028$ ). The presence of MetS was not significantly related to cognitive impairment (OR adjusted for age and sex 0.67; 95\% CI 0.37-1.20; $p=0.175$; Table 5). 
Table 1. Characteristics of respondents and cognitive impairment

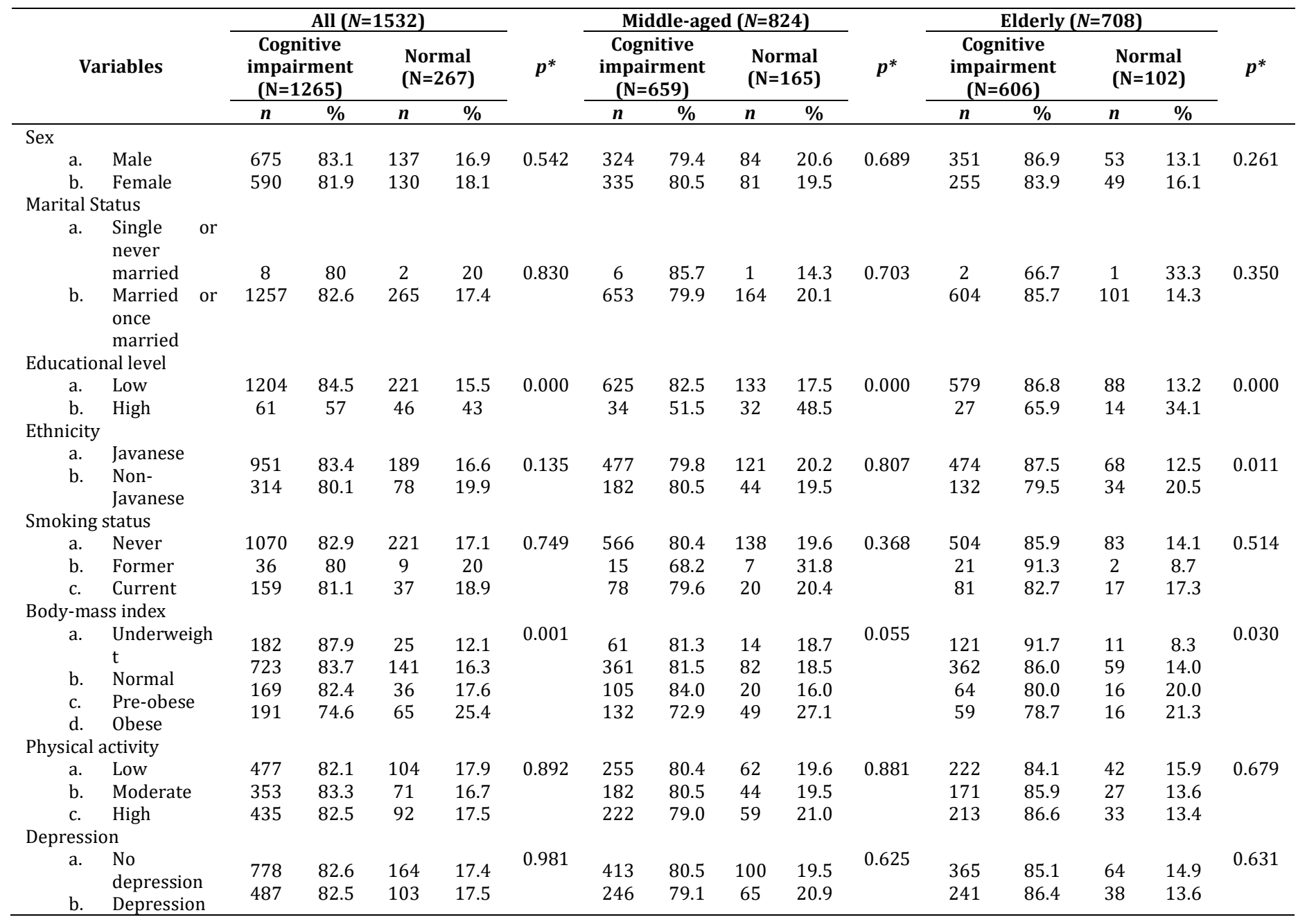

Table 2. Associations between components of metabolic syndrome (MetS) and cognitive impairment

\begin{tabular}{|c|c|c|c|c|c|c|c|c|c|c|c|c|c|c|c|}
\hline \multirow{3}{*}{ Component of MetS } & \multicolumn{4}{|c|}{ All $(N=1532)$} & \multirow{3}{*}{$p^{*}$} & \multicolumn{4}{|c|}{ Middle-aged $(N=824)$} & \multirow{3}{*}{$p^{*}$} & \multicolumn{4}{|c|}{ Elderly $(N=708)$} & \multirow{3}{*}{$p^{*}$} \\
\hline & \multicolumn{2}{|c|}{$\begin{array}{c}\text { Cognitive } \\
\text { impairment } \\
(N=1265)\end{array}$} & \multicolumn{2}{|c|}{$\begin{array}{l}\text { Normal } \\
(N=267)\end{array}$} & & \multicolumn{2}{|c|}{$\begin{array}{c}\text { Cognitive } \\
\text { impairment } \\
(N=659)\end{array}$} & \multicolumn{2}{|c|}{$\begin{array}{l}\text { Normal } \\
(\mathrm{N}=165)\end{array}$} & & \multicolumn{2}{|c|}{$\begin{array}{c}\text { Cognitive } \\
\text { impairment } \\
(N=606)\end{array}$} & \multicolumn{2}{|c|}{$\begin{array}{l}\text { Normal } \\
(\mathrm{N}=102)\end{array}$} & \\
\hline & $n$ & $\%$ & $n$ & $\%$ & & $n$ & $\%$ & $n$ & $\%$ & & $n$ & $\%$ & $n$ & $\%$ & \\
\hline Central obesity & 566 & 44.7 & 140 & 52.4 & 0.026 & 324 & 49.2 & 90 & 54.5 & 0.251 & 242 & 39.9 & 50 & $\begin{array}{c}49 . \\
0\end{array}$ & 0.106 \\
\hline High blood pressure & 1143 & 90.4 & 236 & 88.4 & 0.389 & 592 & 89.8 & 144 & 87.3 & 0.417 & 551 & 90.9 & 92 & $\begin{array}{c}90 . \\
2\end{array}$ & 0.960 \\
\hline High glucose & 51 & 4.0 & 15 & 5.6 & 0.320 & 27 & 4.1 & 8 & 4.8 & 0.832 & 24 & 4.0 & 7 & 6.9 & 0.287 \\
\hline Dyslipidemia & 30 & 2.4 & 13 & 4.9 & 0.041 & 19 & 2.9 & 6 & 3.6 & 0.802 & 11 & 1.8 & 7 & 6.9 & 0.008 \\
\hline
\end{tabular}


Policy Implementation Strategy of West Bandung Regency Health Office in Stunting Intervention During COVID-19 Pandemic

Table 4. Multivariate logistic regression of components of metabolic syndrome (MetS) associated with cognitive impairment

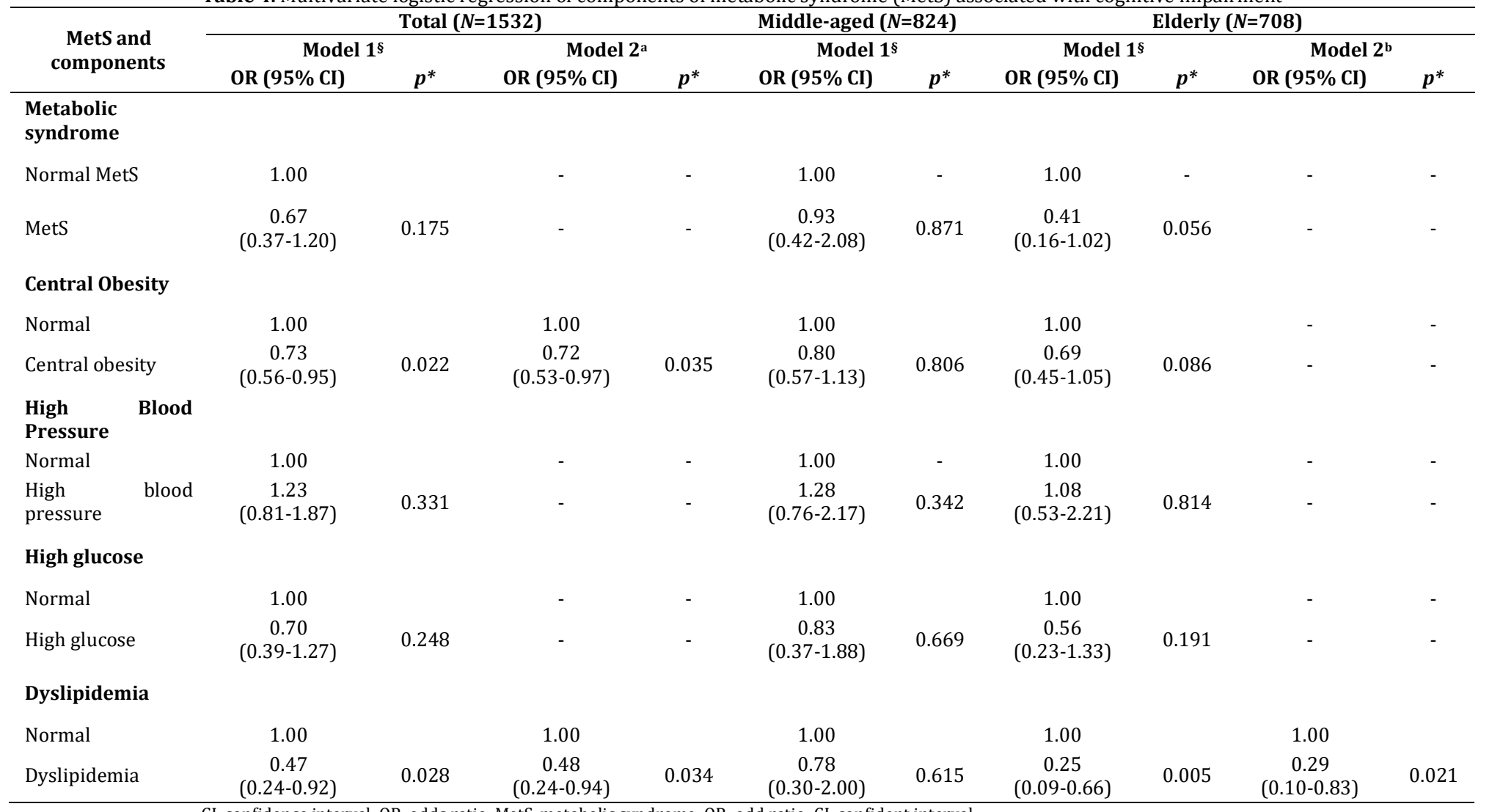

CI, confidence interval; OR, odds ratio. MetS, metabolic syndrome; OR, odd ratio; CI, confident interval.

§: Model unadjusted model (associated each exposure variable with cognitive impairment). a: Model adjusted with age, sex, central obesity and dyslipidemia.

b: Model adjusted with sex and dyslipidemia. ${ }^{*}$ p, p-value comparison between independent variables (MetS and components) and cognitive impairment with significantly $p<0.05$ using binary logistic regression.

\section{DISCUSSION}

We found that individual components of MetS including central obesity and dyslipidemia (cholesterol treatment) were independently associated with cognitive impairment among middle-aged and elderly Indonesians. These results differed from those of previous studies (23-26), which reported that elevated triglycerides and high blood pressure were significantly associated with cognitive impairment. In the current study, we demonstrated that cognitive impairment among middle-aged and elderly Indonesians was affected by components of MetS, age, sex, sociodemographic variables.

Prolonged obesity in adults may lead to the development of atherosclerosis during middle age (27). Some researchers suggested that the risk of MetS increases after middle age, because MetS affects the aging process as it progresses, and the risk of MetS increases as well as the risk of CVDs $(28,29)$. Management of MetS in persons of all age groups is required. Because the aging process is accelerated during this middle-aged period, control needs to focus on preventing CVDs and MetS (30). The progression of obesity in middle age predicts the occurrence of moderate cognitive decline at a later age following adjustment for natural cognitive ageing $(24,31)$.

Interestingly, we found that central obesity was less closely associated with cognitive impairment. Otherwise, central obesity was concluded to be a protective factor. This 
finding is similar to that of previous studies, particularly for participants who are obese (32-34). Many studies of neurodegeneration found that greater weight or BMI in dementia patients with Alzheimer's disease (AD) was associated with an increased volume of the medial cortex, which is associated with improved cognitive scores (35). The potential mechanisms of the association of being overweight with cognitive impairment are not immediately apparent. Two alternative mechanisms might explain the beneficial impacts of being overweight on cognitive impairment in the elderly. First, leptin is predominantly secreted by adipose tissues and can affect higher cognitive function, then it was shown to enhance learning and memory output in mice by controlling hippocampal synaptic plasticity and amyloid $\beta$-processing (3638). Second, elderly people who are overweight have a lower chance of mortality than those underweight or average-weight individuals. Thus, relative to being of average weight or underweight in later life, being overweight tends to suggest a better health condition. In contrast, a higher BMI in the middle-aged group is associated with cardiovascular and metabolic risk factors related to increased risks of cognitive impairment (39).

Central obesity is a component of MetS, which also includes IR, hyperglycemia, dyslipidemia, and hypertension (40). We found that dyslipidemia or cholesterol treatment was less likely to be associated with cognitive impairment especially in the elderly category. However, another study found that central obesity was not related to cognitive function, because central nervous system alterations related to motor function, metabolism, and fatigue might be affected by frailty $(24,41)$. In addition, there were no significant associations of cognitive impairment and other individual components of MetS, including high blood sugar (diabetes treatment). A previous study also reported a lack of significant associations of cognitive impairment with various individual components, but together they posed a significant negative impact on cognitive function (42). In this study, age might have been a confounder in the associations between components of MetS. Age-related changes in body fat distribution might not be reflected in simple anthropometric measures such body weight and WC $(43,44)$.

In our study, there are several important strengths. First, this is the first report on cognitive impairment among Indonesian population. These results can be early detection to prevent cognitive impairment progress to dementia among middle-aged and elderly Indonesian as changing the modifiable risk factors. Second, we used a large number of participants and our data were nationwide survey, so that these results can be used as a reference because it representative of the Indonesian population. Nevertheless, we have limitations in our study. First, due to a crosssectional design study may not fully assess the cause-effect relationship cannot be drawn. Second, we measure obesity used waist circumference as a single parameter. Previous study showed that using waist circumference as a single marker is considered poor indicator of cardio metabolic health because obesity in the elderly need adjusted for body composition which consist of body mass (skeletal muscle mass, fat mass, and fat-free mass). In the future, prospective cohort design studies using the IFLS wave 4 (2000) to IFLS wave $5(2014 / 2015)$ are needed.

\section{CONCLUSION}

In conclusion, our study showed that central obesity and dyslipidemia were positively associated with cognitive impairment among middle-aged and elderly Indonesians Our conclusion is helpful in better identifying Indonesian population those who may 
be a higher risk for cognitive impairment and reemphasize the importance of early detection in the middle-aged group to manage the risk factors including components MetS and lifestyle. However, the mechanisms underlying of these results require further investigations in a longitudinal study.

\section{CONFLICTS OF INTEREST}

The authors declare that there were no conflicts of interest in this study.

\section{ACKNOWLEDGEMENT}

The authors are thankful to the RAND Corporation in collaboration with Lembaga Demografi, University of Indonesia, University of California, Los Angeles (UCLA) in the USA, and the University of Gadjah Mada Center for Population and Policy Studies for providing these data (IFLS-5).

\section{REFERENCES}

1. Rosiyati, E. and Sartika, R. 2020. Dominant Factor of Obesity in Indonesia Population Aged 36-65 Years (Data Analysis IFLS 2014). Research \& Reviews: A Journal of Health Professions 10: 23-28.

2. Fox, A., Feng, W., Asal, V. 2019. What is Driving Global Obesity Trends? Globalization or "Modernization"? Globalization and Health 15, 32, DOI:10.1186/s12992-0190457-y.

3. Agency, C.I. 2017. The World Factbook: Indonesia.

4. UNFPA, B.B. 2013. Indonesia Population Projection 2010-2035.

5. Oddo, V.M., Maehara, M., Rah, J.H. 2019. Overweight in Indonesia: an Observational Study of Trends and Risk Factors among Adults and Children. BMJ, 9, e031198.

6. Rachmi, C., Li, M., Baur, L.A. 2017. Overweight and obesity in Indonesia: Prevalence and Risk Factors—a Literature Review. Public Health 147: 20-29.

7. Unit, E.I. 2017. Tackling Obesity in ASEAN: Prevalence, Impact, and Guidance on Interventions. Asia Roundtable Food Innov Improv Nutr [Internet].

8. Schröders, J., et al. 2017. How is Indonesia Coping with Its Epidemic of Chronic Noncommunicable Diseases? A Systematic Review with Meta-analysis. PloS one, 12, e0179186.

9. Maharani, A. dan Tampubolon, G. 2016. National Economic Development Status May Affect The Association between Central Adiposity and Cognition in Older Adults. PloS one, 11, e0148406.

10. Perona, J.S., et al. 2019. Waist Circumference and Abdominal Volume Index are The Strongest Anthropometric Discriminators of Metabolic Syndrome in Spanish Adolescents. European Journal of Clinical Investigation, 49, e13060.

11. United Nations, D.o.E.a.S.A., Population Division. 2015. World Population Ageing Highlights (ST/ESA/SER.A/368).

12. Statistik, B.P.J.D.d.h.s.b.g.i.i.p.d.p. 2016. Survei Penduduk Antar Sensus (SUPAS).

13. Kemenkes, R.J.O.h.w.d.g.i.r.d.i.-t.m.r.H.R. 2018. Hasil utama RISKESDAS 2018.

14. J. Strauss, F.W., and B. Sikoki. 2016 The Fifh Wave of the Indonesia Family Life Survey (IFLS5): Overview and Field Report: 1.

15. Alberti, K.G., et al. 2019. Harmonizing the Metabolic Syndrome: a Joint Interim Statement of The International Diabetes Federation Task Force on Epidemiology and Prevention; National Heart, Lung, and Blood Institute; American Heart Association; World Heart Federation; International Atherosclerosis Society; and International 
Association for the Study of Obesity. Circulation Vol. 120: 1640-1645, DOI:10.1161/circulationaha.109.192644.

16. Brandt, J., Spencer, M.. Folstein, M. 1988. The Telephone Interview for Cognitive Status. Cognitive and Behavioral Neurology: 1.

17. Fong, T.G., et al. 2009. Telephone Interview for Cognitive Status: Creating a Crosswalk with The Mini-Mental State Examination. Alzheimers Dement Vol. 5: 492-497, DOI:10.1016/j.jalz.2009.02.007.

18. Indonesia, D.J.D.K.R. Masyarakat DG Petunjuk Teknis Pemantauan Status Gizi Orang Dewasa Dengan Indeks Massa Tubuh. 27.

19. González, P., et al. 2017. Measurement Properties of The Center for Epidemiologic Studies Depression Scale (CES-D 10): Findings from HCHS/SOL. Psychological Assessment Vol. 29: 372-381, DOI:10.1037/pas0000330.

20. Kilburn, K., et al. 2018. Examination of Performance of The Center for Epidemiologic Studies Depression Scale Short Form 10 among African youth in poor, rural households. BMC psychiatry Vol. 18: 201.

21. Pengpid, S., Peltzer, K., Susilowati, I.H. 2019. Cognitive Functioning and Associated Factors in Older Adults: Results from the Indonesian Family Life Survey-5 (IFLS-5) in 2014-2015. Curr Gerontol Geriatr Res 2019: 4527647-4527647, DOI:10.1155/2019/4527647.

22. Liu, X., et al. 2017. Dose-Response Association Between Physical Activity and Incident Hypertension: A Systematic Review and Meta-Analysis of Cohort Studies. Hypertension Vol. 69: 813-820, DOI:10.1161/hypertensionaha.116.08994.

23. Isaura, E.R., Chen, Y.-C., Yang, S.-H. 2018. The Association of Food Consumption Scores, Body Shape Index, and Hypertension in a Seven-Year Follow-Up among Indonesian Adults: A Longitudinal Study. International Journal of Environmental Research and Public Health Vol. 15: 175.

24. Feinkohl, I., et al. 2019. Associations of The Metabolic Syndrome and Its Components with Cognitive Impairment in Older Adults. BMC Geriatrics Vol. 19: 77.

25. Lin, E., Yang, A.C., Tsai, S.-J. 2017. Association Between Metabolic Syndrome and Cognitive Function in Old Adults in a Taiwanese Population. Vol. 31: 232-240+ iv.

26. Liu, Z., et al. 2018. The Association Between Body Mass Index, Waist Circumference, Waist-Hip Ratio and Cognitive Disorder in Older Adults. Journal of Public Health Vol. 41: 305-312, D0I:10.1093/pubmed/fdy121 \%J Journal of Public Health.

27. Lee, Y. and An, J. 2020. Sex Differences in Risk Factors for Metabolic Syndrome in the Korean Population. International Journal of Environmental Research and Public Health Vol. 17: 9513.

28. Bonomini, F., Rodella, L.F., Rezzani, R. 2015. Metabolic Syndrome, Aging and Involvement of Oxidative Stress. Aging and Disease Vol. 6: 109.

29. Kazlauskaite, R., et al. 2020. Is Midlife Metabolic Syndrome Associated with Cognitive Function Change? The Study of Women's Health Across the Nation. The Journal of Clinical Endocrinology \& Metabolism Vol. 105: e1093-e1105.

30. Yi, Y. and An, J. 2020. Sex Differences in Risk Factors for Metabolic Syndrome in the Korean Population. International Journal of Environmental Research and Public Health Vol. 17: 9513.

31. Borshchev, Y.Y., Uspensky, Y.P., Galagudza, M.M. 2019. Pathogenetic Pathways of Cognitive Dysfunction and Dementia in Metabolic Syndrome. Life Sciences Vol. 237: 116932.

32. Vidyanti, A.N., et al. 2020. Obesity Is Less Frequently Associated with Cognitive Impairment in Elderly Individuals: A Cross-Sectional Study in Yogyakarta, Indonesia. Nutrients Vol. 12: 367. 
33. Strandberg, T.E., et al. 2013. The "Obesity Paradox," Frailty, Disability, and Mortality in Older Men: A Prospective, Longitudinal Cohort Study. American Journal of Epidemiology Vol. 178: 1452-1460.

34. Wang, X., et al. 2019. Association Between Individual Components of Metabolic Syndrome and Cognitive Function in Northeast Rural China. American Journal of Alzheimer's Disease \& Other Dementiasr Vol. 34: 507-512, DOI: $10.1177 / 1533317519865428$.

35. Grundman, M.. et al. 1996. Low Body Weight in Alzheimer's Disease is Associated with Mesial Temporal Cortex Atrophy. Neurology Vol. 46: 1585-1591.

36. Forny-Germano, L., De Felice, F.G., Vieira, M.N.d.N.J.F.i.n. 2019. The Role of Leptin and Adiponectin in Obesity-Associated Cognitive Decline and Alzheimer's Disease. Vol. 12: 1027.

37. Feinkohl, I., et al. 2020. Plasma Leptin, but not Adiponectin, is Associated with Cognitive Impairment in Older Adults. Vol. 120, 104783.

38. Mejido, D.C., et al. 2020. Insulin and Leptin as Potential Cognitive Enhancers in Metabolic Disorders and Alzheimer's Disease. 108115.

39. Hou, Q., et al. 2019. Associations between Obesity and Cognitive Impairment in The Chinese Elderly: An Observational Study. Clin Interv Aging Vol. 14: 367-373, DOI:10.2147/CIA.S192050.

40. Chang, Y.-C., et al. 2019. High TSH Level within Normal Range is Associated with Obesity, Dyslipidemia, Hypertension, Inflammation, Hypercoagulability, and The Metabolic Syndrome: A Novel Cardiometabolic Marker. Journal Of Clinical Medicine Vol. 8: 817.

41. Tamura, Y., et al. 2020. Nutrition Management in Older Adults with Diabetes: A Review on the Importance of Shifting Prevention Strategies from Metabolic Syndrome to Frailty. 12, 3367.

42. Mehra, A., et al. 2020. Association of Mild Cognitive impairment and Metabolic Syndrome in patients with Hypertension. Asian Journal of Psychiatry, 102185.

43. Cheong, K.C., et al. 2015. The Discriminative Ability of Waist Circumference, Body Mass Index and Waist-To-Hip Ratio in Identifying Metabolic Syndrome: Variations by Age, Sex and Race. Diabetes \& Metabolic Syndrome: Clinical Research \& Reviews Vol. 9: 74-78, DOI:https://doi.org/10.1016/j.dsx.2015.02.006.

44. Atti, A.R., et al. 2019. Metabolic Syndrome, Mild Cognitive Impairment, and Dementia: A Meta-Analysis of Longitudinal Studies. Vol. 27: 625-637. 